\title{
Use of Apomorphine in Parkinsonian Patients with Neuropsychiatric Complications to Oral Treatment
}

\author{
CATHERINE ELLISt, GILBERT LEMMENSt, J. DAVID PARKESt, R. J. ABBOTT $\ddagger$ I. F. PYEł, \\ P. NIGEL LEIGH† AND K. RAY CHAUDHURI†
}

Received for publication 7 April 1997

\begin{abstract}
Neuropsychiatric side effects often complicate anti-Parkinsonian therapy and pose a significant problem in the optimal management of idiopathic Parkinson's disease. Several publications report a relative lack of neuropsychiatric side effects in Parkinsonian patients treated with subcutaneous apomorphine. To investigate this further, we have used subcutaneous apomorphine to treat 12 non-demented IPD patients with previous oral drug-related neuropsychiatric problems.

Treatment with apomorphine allowed alteration of anti-Parkinsonian medication and led to the abolition or reduction of neuropsychiatric complications in all patients. The mechanism remains unclear but may be due, in part, to a reduction in oral medication or a psychotropic action of apomorphine, possibly due to the piperidine moiety in its structure, or both. (C) 1997 Elsevier Science Ltd
\end{abstract}

Parkinson's dișease Neuropsychiatric Apomorphine

\section{INTRODUCTION}

Levodopa, apomorphine and dopamine agonist ergot derivatives, such as lisuride and pergolide, differ in their anti-Parkinsonian effects, pharmacokinetics and side effect profile. The use of apomorphine, with achievement of steady state plasma drug levels, results in stable control of the symptoms of Parkinson's disease in chronically levodopa treated patients with frequent and disabling dose-related motor response fluctuations [1]. In advanced Parkinson's disease levodopa related motor response fluctuations may be associated with variable psychomotor responses. In addition to these on-off fluctuations, one third of subjects with advanced Parkinson's disease show a wide range of neuropsychiatric side effects including visual hallucinosis, paranoid behaviour, changes in awareness and depression [2]. These factors may be related to progressive pathology or the development of cortical Lewy body disease, but also to the use of levodopa.

tDepartment of Clinical Neurosciences, Institute of Psychiatry and King's College Srhool of Medicine and Dentistry, I.ondon, U.K $\ddagger$ Neurology Department, Leicester Royal Infirmary, Leicester, U.K. Address correspondence to: Dr C. M. Ellis, Department of Neurology, Institute of Psychiatry, De Crespigny Park, London SE5 8AF, U.K. Tel. (+44) (0)171 919 3407; Fax. (+44) (0)171 703 9989.
The use of different oral dopamine agonists can result in the achievement of an improved clinical profile in individual subjects, although neuropsychiatric side effects of drugs, such as lisuride or bromocriptine, may complicate an otherwise acceptable control of Parkinsonism. Apomorphine, considered to be the most potent dopamine receptor agonist, has been shown to be unable to activate schizophrenic symptoms or induce psychosis in nonschizophrenics [3]. Furthermore, Tamminga et al. [4] have reported an improvement in psychotic features in neuroleptic-responsive schizophrenics treated with apomorphine, although this remains contraversial. Recent studies using subcutaneous apomorphine to treat refractory on-off oscillations in Parkinson's disease have also reported a relative paucity of neuropsychiatric complications, though no formal studies have been undertaken $[5,6]$. We have been using subcutaneous apomorphine for over 8 years and have been impressed by the relative lack of neuropsychiatric complications in PD patients with on-off oscillations treated with subcutaneous apomorphine and optimisation of oral therapy. We report here our experience in an open study of the use of apomorphine in Parkinson's disease patients with severe and varied neuropsychiatric complications on oral therapy. 


\section{PATIENTS AND METHODS}

\section{Patients}

Subjects included in this study had probable idiopathic Parkinson's Disease, satisfying the UK Brain Bank criteria and had severe neuropsychiatric complications on oral anti-Parkinsonian medication, some requiring hospital admission for levodopa induced psychosis $(n=2)$ and hallucinations $(n=3)$ [7]. Prior to apomorphine therapy all subjects had formal neuropsychiatric evaluation using the mentation, behaviour and mood section of the Unified Parkinson's Disease Rating Scale (UPDRS) and assessment of performance and verbal IQ using a structured interview [8]. Neuropsychiatric evaluation at off stage was not possible because of severe bradyphrenia, bradykinesia and rigidity. Off period neuropsychiatric complications included screaming $(n=2)$ and hallucinations and paranoia $(n=2)$. Neuropsychiatric complications required reduction of levodopa and oral dopamine agonists in all patients prior to commencing apomorphine and two patients with severe levodopa intolerance remained off levodopa at the expense of worsening control of the Parkinsonian movement disorder. All subjects had severe motor response fluctuations related to chronic L-dopa therapy and were treated with apomorphine over a mean period of 28 months, from 1989 to 1995. During this time, 12 non-demented IPD patients (mean age \pm SD $59 \pm 14 \mathrm{y}$, range 39-78; duration of IPD $11 \pm 6 \mathrm{y}$, range 3-23) specifically selected for intolerance to oral therapy because of neuropsychiatric complications were treated with apomorphine. The patient details are shown in Table 1.
Reasons for the introduction of apomorphine were as follows:

a: Neuropsychiatric complications when increasing anti-Parkinsonian medication, particularly visual hallucinations and agitation/manic episodes.

b: Severe motor response fluctuations, often with unpredictable off periods.

c: Severe L-dopa induced dyskinesias.

The exact treatment prior to apomorphine therapy and whilst on apomorphine is shown in Table 2. Prior to treatment with subcutaneous apomorphine, the L-dopa dosage was $704.2+497 \mathrm{~g}$ (mean $\pm \mathrm{SD}$ ). Nine patients took oral dopamine agonists. Manipulations with oral therapy proved unsuccessful in reducing the neuropsychiatric complications prior to the commencement of apomorphine therapy. Ten of the patients had neuropsychiatric symptoms on their medications before apomorphine was started and two of the patients developed symptoms as oral therapy was increased to control motor fluctuations and therefore could not tolerate the increase in medication. One patient, intolerant to L-dopa and oral dopamine agonists due to neuropsychiatric side effects, remains on apomorphine alone. At the time of writing, the mean duration of treatment with apomorphine is 28 months (range 8-72 months).

\section{Apomorphine administration}

The patients were admitted to hospital to monitor the pattern of on-off fluctuations and for assessment of apomorphine responsiveness. All patients were

TABLE 1. Neuropsychiatric complications pre and post-apomorphine treatment in 12 patients with idiopathic Parkinson's disease

\begin{tabular}{|c|c|c|c|c|c|c|}
\hline \multirow[t]{2}{*}{$\mathrm{Pt}$} & \multirow[t]{2}{*}{ Age } & \multirow[t]{2}{*}{ Sex } & \multirow{2}{*}{$\begin{array}{l}\text { Duration } \\
\text { of } \mathrm{PD} \\
\text { (years) }\end{array}$} & \multirow[t]{2}{*}{$H$ and $Y$} & \multicolumn{2}{|c|}{ Neuropsychiatric complications } \\
\hline & & & & & Pre-apomorphine & Post-apomorphine \\
\hline 1 & 64 & $\mathrm{~m}$ & 4 & 4 & confusion & nil \\
\hline 2 & 70 & $\mathrm{f}$ & 15 & 4 & complex visual hallucinations & nil, apomorphine stopped due to increased falls \\
\hline 3 & 73 & f & 18 & 3 & visual hallucinations, disorientated & nil \\
\hline 4 & 39 & $\mathrm{~m}$ & 23 & 4 & $\begin{array}{l}\text { behavioural problems, inappropriate } \\
\text { sexuality, confusion, disorientated }\end{array}$ & nil \\
\hline 5 & 43 & $\mathrm{~m}$ & 8 & 4 & on-off paranoia, nightmares & $\begin{array}{l}\text { nil, apomorphine stopped due to persistent } \\
\text { nausea }\end{array}$ \\
\hline 6 & 46 & $\mathrm{~m}$ & 5 & 4 & $\begin{array}{l}\text { visual hallucinations, on-off paranoia, } \\
\text { mental akathisia }\end{array}$ & $\begin{array}{l}\text { visual hallucinations reduced but persistent, } \\
\text { mental akathisia returned on very high doses } \\
\text { apo, responded to reducing dose }\end{array}$ \\
\hline 7 & 56 & m & 15 & 4 & visual hallucinations, anxiety, depression & $\begin{array}{l}\text { initial confusion after starting apomorphine, } \\
\text { responded to reducing Sinemet }\end{array}$ \\
\hline 8 & 50 & $\mathrm{~m}$ & 3 & 3 & nightmares, confusion, mental akathisia & $\begin{array}{l}\text { no confusion, mental akathisia and nightmares } \\
\text { improved }\end{array}$ \\
\hline 9 & 46 & $\mathrm{f}$ & 8 & 4 & $\begin{array}{l}\text { paranoid delusions, visual hallucinations, } \\
\text { aggression }\end{array}$ & nil \\
\hline 10 & 67 & $\mathrm{f}$ & 10 & 4 & visual hallucinations & nil \\
\hline 11 & 74 & $\mathrm{~m}$ & 12 & 4 & psychosis, complex visual hallucinations & occasional nocturnal confusion only \\
\hline 12 & 78 & $\mathrm{~m}$ & 10 & 3 & visual hallucinations, inappropriate speech & $\begin{array}{l}\text { no hallucinations, occasional inappropriate } \\
\text { speech }\end{array}$ \\
\hline
\end{tabular}


TABLE 2. Anti-Parkinsonian treatment before and after stabilisation on apomorphine in 12 subjects with idiopathic Parkinson's disease

\begin{tabular}{|c|c|c|c|c|c|c|}
\hline \multirow[t]{2}{*}{ Patient } & \multicolumn{3}{|c|}{ Anti-Parkinsonian treatment pre-apomorphine therapy } & \multicolumn{3}{|c|}{$\begin{array}{c}\text { Total anti-Parkinsonian treatment when established on } \\
\text { apomorphine }\end{array}$} \\
\hline & $\begin{array}{l}\text { Total daily } \\
\text { levodopa }\end{array}$ & $\begin{array}{l}\text { Dopamine } \\
\text { agonist }\end{array}$ & Other & $\begin{array}{l}\text { Apomorphine total mg } \\
\text { per day }\end{array}$ & $\begin{array}{l}\text { Total daily } \\
\text { levodopa }\end{array}$ & Other \\
\hline 1 & $200 \mathrm{mg}$ & pergolide & & $100 \mathrm{mg}$ over $12 \mathrm{~h}$ & $200 \mathrm{mg}$ & \\
\hline 2 & $200 \mathrm{mg}$ & pergolide & amantadine & $60 \mathrm{mg}$ over $10 \mathrm{~h}$ & $200 \mathrm{mg}$ & amantadine \\
\hline 3 & $800 \mathrm{mg}$ & - & selegiline & Penject $25 \mathrm{mg}$ & $300 \mathrm{mg}$ & \\
\hline 4 & $1800 \mathrm{mg}$ & pergolide & & Penject $60 \mathrm{mg}$ & $1250 \mathrm{mg}$ & riserpidone \\
\hline 5 & $900 \mathrm{ming}$ & - & selegiline & Penjecl $10 \mathrm{mg}$ & $800 \mathrm{mg}$ & \\
\hline 6 & $1000 \mathrm{mg}$ & pergolide & selegiline & Penject $25 \mathrm{mg}$ & $1100 \mathrm{mg}$ & \\
\hline 7 & $1300 \mathrm{mg}$ & bromocriptine & $\begin{array}{l}\text { amantadine } \\
\text { benzhexol }\end{array}$ & $\begin{array}{l}114 \mathrm{mg} \text { over } 24 \mathrm{~h} \text { plus } \\
\text { penject } 8 \mathrm{mg}\end{array}$ & $900 \mathrm{mg}$ & amantadine \\
\hline 8 & $800 \mathrm{mg}$ & pergolide & amantadine & $36 \mathrm{mg}$ over $12 \mathrm{~h}$ & $800 \mathrm{mg}$ & - \\
\hline 9 & $350 \mathrm{mg}$ & bromocriptirle & & $36 \mathrm{mg}$ over $12 \mathrm{~h}$ & & \\
\hline 10 & $400 \mathrm{mg}$ & bromocriptine & & $40 \mathrm{mg}$ over $12 \mathrm{~h}$ & $300 \mathrm{mg}$ & \\
\hline 11 & $200 \mathrm{mg}$ & bromocriptine & benzhexol & $36 \mathrm{mg}$ over $12 \mathrm{~h}$ & $150 \mathrm{mg}$ & \\
\hline 12 & $500 \mathrm{mg}$ & & $\begin{array}{l}\text { selegiline } \\
\text { amantadine }\end{array}$ & $30 \mathrm{mg}$ over $10 \mathrm{~h}$ & $600 \mathrm{mg}$ & \\
\hline
\end{tabular}

pre-treated with the peripheral dopamine antagonist, domperidone, for three days to prevent nausea. Oral dopamine agonists were stopped in all patients prior to treatment (mean 7 days, range 3-21 days) with apomorphine. Apomorphine was then administered by subcutaneous injection to the anterior abdominal wall at a dose of $1 \mathrm{mg}$, increasing by $1 \mathrm{mg}$ increments every $20 \mathrm{~min}$ until a maximum dose of $10 \mathrm{mg}$ or a clinical effect (greater than 50\% improvement in motor activity scores using a standard apomorphine and levodopa challenge protocol) was obtained. This threshold determined the dosage used for the subsequent treatment, delivered either as a continual infusion using a Graseby pump over a $12 \mathrm{~h}$ period in the day or by a 'Penject' system. The rate was increased in the infusion pump until the optimal daily dose was achieved (mean \pm SD $56.5 \pm 32.6 \mathrm{mg}$ ), and patients were instructed on how to give additional boluses if they felt the fixed rate delivery was inadequate. The 'Penject' system was used when patients were able to predict off periods, injections being self-administered to the anterior abdominal wall (mean \pm SD $25.6 \pm 20.8 \mathrm{mg}$ ). All patients were specifically questioned and observed for neuropsychiatric side effects and underwent post apomoprhine neuropschometry and UPDRS assessments between 3-6 months after commencing apomorphine. The development of erythematous nodules at the injection site, a recognised complication of subcutaneous apomorphine, was reduced by changing the needle insertion site every second day for the infusion pump delivery system and paying careful attention to cleanliness when placing the needle subcutaneously. No patient needed to discontinue the therapy because of this complication.

\section{Apomorphine failures}

Two patients discontinued apomorphine: one had continued nausea despite concomitant treatment with domperidone; one reported an increase in the number of falls possibly exacerbated by the increase in mobility on apomorphine.

\section{RESULTS OF SUBJECTS TOLERANT OF, AND ESTABLISHED ON, APOMORPHINE}

The results are shown in Table 1. When stabilised on subcutaneous apomorphine (mean dose \pm SD: $48.5 \pm 33.2 \mathrm{mg} / 24 \mathrm{~h}$, range $25-124)$, there was an abolition or reduction of neuropsychiatric complications and a significant improvement in off periods ( $>60 \%$ reduction in off periods) in all patients. Mean Hoehn and Yahr staging improved from 4 to 2.5 and two patients reported being able to walk outdoors and do shopping for the first time in $4 \mathrm{y}$. The mean L-dopa dosage could be reduced by $20 \%$ (mean \pm SD $566.7 \pm$ $392 \mathrm{mg}$ ). Three subjects required additional oral dopamine agonist therapy without recrudescence of neuropsychiatric complications. No new neuropsychiatric symptoms were observed while patients were on apomorphine. One patient reported night time confusion but had experienced psychosis and visual hallucinations throughout the day on oral therapy. One patient intolerant to L-dopa due to the development of severe paranoid delusions is now controlled on apomorphine only. One patient increased his apomorphine to $140 \mathrm{mg}$ over $24 \mathrm{~h}$ and developed mental akathisia, which he described as feeling his thoughts 'racing around inside my head'. He has been converted to Penjects which at a dose of 20-30 mg per day are able to control his severe off periods without neuropsychiatric complications. Patient 4 with juvenile onset Parkinson's Disease has now developed signs of sphincter incontinence and some cognitive impairment. He still remains sensitive to apomoprhine and continues in apomorphine although Risperidone, 
an atypical neuroleptic has been added (24 months after treatment with apomorphine was started) to control his mental symptoms.

\section{DISCUSSION}

Our preliminary observations suggest that patients on oral treatment complicated by neuropsychiatric side effects may benefit from apomorphine with a reduction in these side effects and in the motor response fluctuations. Apomorphine has been usefully administered to mental patients for more than ninety years since Douglas reported its efficacy as a sedative in 1907 [9]. Corsini and colleagues in 1981 reported marked improvements in psychosis in schizophrenics given apomorphine in open and double blind trials [3]. Furthermore, Corsini noted that those patients with thought disorder, multiple delusions and hallucinations were most helped by apomorphine administration. Whether the reduction in neuropsychiatric side effects in Parkinson's disease patients on subcutaneous apomorphine is related to the potential anti-psychotic action of apomorphine remains speculative and controversial. Although our study and a previous study by Stibe et al. [1] suggest that apomorphine treatment causes less neuropsychiatric side effects in PD, yet Ruggieri and colleagues reported severe mental confusion and hallucinations in patients treated with L-dopa and apomorphine, although the patients enrolled in this study had all been pre-treated with lisuride, a compound wellknown to cause severe mental side effects [10].

In our study, all patients who tolerated apomorphine reported a reduction or a complete lack of neuropsychiatric side effects. In addition, apomorphine significantly improved the Parkinsonian control and the activities of daily living parameters. This approach has avoided the concomitant use of newer neuroleptics, such as risperidone or clozapine, which have significant side effects and are reported to have little effect on motor symptoms. Three patients who could not tolerate oral dopamine agonists prior to apomoprhine, could do so following apomoprhine therapy without any significant neuropsychiatric complications. Furthermore, one patient remains on apomoprhine alone (72 months at the time of writing), having been unable to tolerate levodopa or oral dopamine agonists due to severe psychosis and hallucinations.

We thus believe from our observations that patients with IPD, intolerant to oral therapy because of neuropsychiatric complications, should be given a trial of apomorphine infusion as this may improve their Parkinsonian state and neuropsychiatric symptoms.

The mechanism remains uncertain, but may be due to a reduction in concomitant oral therapy, reduction in off periods or a psychotropic action of apomorphine, possibly due to the effect on different dopamine receptor subtypes or to an anti-psychotic action of the piperidine moiety of apomorphine. In this study, apomorphine was tolerated by one subject who was intolerant to L-dopa and to oral dopamine agonists because of severe agitation and psychosis. This supports our observation that apomorphine may indeed have a psychotropic action of its own, although this may well be clinically insiginificant because of the almost invariable concomitant reduction in levodopa or oral dopamine agonist doseage after apomorphine is commenced. However, our single patient on apomorphine therapy alone provides further support of our hypothesis, as does the fact that three patients could tolerate oral dopamine agonists while on apomorphine only. DuP734, a piperidine analogue, is known to have anti-psychotic actions, and is a selective and potent sigma and 5HT2 receptor ligand with weak D2 affinity [11]. In mice models, DuP734 has little anti-apomorphine effect as measured by its ability to block apomorphine induced climbing [12]. The combination of piperidine and apomorphine would therefore not be antagonistic and may thus lead to differential actions on the psyche and motor responses.

The observations from this open study need to be investigated further with a double blind, placebo controlled study to further examine the role of apomorphine in the treatment of Parkinson's Disease patients with drug induced neuropsychiatric complications.

\section{REFERENCES}

1. Stibe CMH, Kempster PA, Lees AJ, Stern GM. Subcutaneous apomorphine in Parkinsonian on-off oscillations. Lancet 1988; i: $403-406$.

2. Marsden CD, Parkes JD and Quinn N. Fluctuations of disabilities in Parkinson's disease - clinical aspects. In Movement Disorders, eds CD Marsden and S Fahn. Butterworths, London, 1982, pp. 96-122.

3. Corsini GU, Pitzalis GF, Bernardi F, Bocchetta A, Del Zompo M. The use of dopamine agonists in the treatment of schizophrenia. Neuropharmacology 1981; 20: 1309-1313.

4. Tamminga GA, Gotts MD, Thacker GK, Alphs LD, Foster NL. Dopamine agonist treatment of schizophrenic patients with npropylnorapomorphine. Arch. Gen. Psych. 1986; 43 (4): 398-402.

5. Ray Chaudhuri K, Abbott RJ, Millac PAC. Subcutaneous apomorphine for Parkinsonian patients with psychiatric side effects on oral treatment. J. Neurol. Neurosurg. Psychiat. 1990; 54: 372-373.

6. Lees AJ. Dopamine agonists in Parkinson's disease; a look at apomorphine. Fundam. Clin. Pharmacol. 1993; 7: 121-128.

7. Hughes AJ, Daniel SE, Kilford L, Lees AJ. Accuracy of clinical diagnosis of idiopathic Parkinson's disease: a clinico-pathological study of 100 cases. J. Neurol. Neurosurg. Psychiat. 1992; 55: 181-184.

8. Fahn $S$ and Elton R. Members of the UPDRS Development Committee Unified Parkinson's disease rating scale. In Recent Developments in Parkinson's Disease, eds S Fahn, CD Marsden, DM Calne and M Goldstein. Macmillan Healthcare Information, Florham Park, NJ. 1987, pp. 153-164. 
9. Douglas CJ. Apomorphine as an hypnotic. NY Med. J. 1900; 71: 376-378.

10. Ruggieri S, Stocchi F, Carta A, Agnoli A. Side effects of subcutaneous apomorphine in Parkinson's disease. Lancet 1989; i: 566.

11. Martin WR, Eades CE, Thompson JA, Huppler RE. The effects of morphine and naloprine-like drugs in the non-dependent and morphine-dependent chronic spinal dog. J. Pharmacol. Exp. Ther. 1976; 157: 517-532.
12. Cook L, Tam WS, Rohrbach KW. DuP 734 [1-(Cyclopropylmethyl)-4-(2'(4"-Flurophenyl)-2'-Oxoethyl)-Piperidine $\mathrm{HBr}]$, a potential antipsychotic agent: preclinical behavioural effects. J. Pharm. Exp. Ther. 1992; 263 (3): 1159-1166.

Acknowledgements-We gratefully acknowledge the support of Britannia Pharmaceuticals and assistance of Judy Grimshaw. 